\title{
Modelling Water Use of Subtropical Fruit Crops: the Challenges
}

\author{
NJ Taylor, JG Annandale, JT Vahrmeijer, NA Ibraimo, W Mahohoma, \\ Department of Plant Production and Soil Science, University of Pretoria, Private Bag X20, Hatfield 0028, South \\ Africa
}

JT Vahrmeijer

Citrus Research International, P.O. Box 28, Nelspruit 1200, South Africa

MB Gush

CSIR - Natural Resources and the Environment, Hydroscience Research Group, P.O. Box 320, Stellenbosch

7599 , South Africa

RG Allen

Biological and Agricultural Engineering and Civil Engineering, University of Idaho, 3793 N3600 E, Kimberley, ID, 83341, USA

\begin{abstract}
Subtropical fruit crops form an important part of the fruit industry in many countries. Many of these crops are grown in semi-arid regions or subtropical regions where rainfall is seasonal and as a result the vast majority of these perennial, evergreen orchards are under irrigation. This represents a significant irrigation requirement and with more emphasis being placed on the conservation of water and orchard profitability, it is becoming increasingly important to accurately estimate water use of these crops and schedule irrigation accordingly. The FAO-56 procedure is a simple, convenient and reproducible method for estimating water use. However, the transferability of crop coefficients between different orchards and growing regions is not always readily achieved, due largely to differences in canopy size and management practices. In addition, as subtropical crops tend to exhibit a higher degree of stomatal control over transpiration than most other agricultural crops, some measure of canopy or leaf resistance must be taken into account when using models based on atmospheric demand. The challenge is therefore to provide reliable and dynamic estimates of canopy resistance from relatively simple parameters which can be of use to irrigation consultants and farmers for determining the water requirements of these crops. The challenge remains to ensure that these dynamic estimates are realistic and readily applicable to a number of growing regions. The derivation of transpiration crop coefficients, based on canopy cover and height and a dynamic estimate of leaf resistance, provided reasonable estimates of transpiration in three orchards in contrasting climates, suggesting that this approach could prove useful in future for subtropical crops.
\end{abstract}

Keywords: transpiration, transpiration crop coefficients, leaf resistance, vapour pressure deficit, effective fractional cover

\section{INTRODUCTION}

Many subtropical orchards are planted in semi-arid or subtropical regions where rainfall is seasonal and as a result the vast majority of these evergreen, perennial orchards are under irrigation. This represents a significant irrigation requirement. With more pressure being placed on agriculture to reduce water use and with the increase in pollution of natural water resources, it is becoming increasingly important to accurately estimate water use of cultivated crops. 
Water use measurements are too expensive and time-consuming to perform in all crops under all conditions, and as a result various water use models have proved very useful for extrapolating measured data and predicting water use. The crop coefficient $\left(K_{\mathrm{c}}\right)$ approach described by Allen et al. (1998) has been used extensively in irrigation water management and is currently considered the standard method for determining crop water use, due largely to its relative simplicity. However, in tree crops, a linear relationship between the evapotranspiration (ET) from a short, smooth and uniform grass surface and a tall, very rough, clustered orchard canopy may not always hold true (Annandale and Stockle, 1994; Testi et al., 2004). This often means that $K_{\mathrm{c}}$ values derived in one location may not be readily transferable to other locations, which limits the extrapolation of such data to different climatic zones, with different orchard management practices.

In an attempt to make crop coefficients more transferrable between different orchards, Allen and Pereira (2009) developed a procedure for estimating crop coefficients where vegetation density and height varies between orchards. The aim of this paper was therefore to evaluate this procedure for the derivation of orchard specific transpiration crop coefficients $\left(K_{\mathrm{t}}\right)$ for a citrus orchard in the winter rainfall region of South Africa, by comparing derived $K_{\mathrm{t}}$ values with actual $K_{\mathrm{t}}$ values determined from transpiration measurements using sap flow. $K_{\mathrm{t}}$ values, as suggested by Villalobos et al. (2013), were chosen, as $K_{\mathrm{cb}}$ includes some evaporation when the soil surface is dry and only transpiration was measured in this study.

\section{MATERIALS AND METHODS}

Measurements of citrus [Citrus sinensis (L.) Osbeck] water use were conducted in the winter rainfall region of South Africa over a single season (2010/11) at Patrysberg Farm in the Western Cape Province (32 $2^{\circ} 7^{\prime} 15.43^{\prime \prime} \mathrm{S}$ and $18^{\circ} 58^{\prime} 3.58^{\prime}$ ' E, 149 m.a.s.1., orchard area 3.9 ha) in a commercial orchard planted with 14-year-old 'Rustenburg' Navel oranges. The area receives an average annual rainfall of $200 \mathrm{~mm}$. The trees were grafted on 'Troyer' citrange rootstocks and planted at a spacing of $5 \times 2.5 \mathrm{~m}$. Average tree height was $3.3 \mathrm{~m}$ and average effective fractional cover $\left(f_{\mathrm{c} \text { eff }}\right)$ was 0.88 . The orchard was drip irrigated, with two drip lines per tree row using pressure-compensating emitters spaced $0.8 \mathrm{~m}$ apart with a discharge of $1.8 \mathrm{~L} \mathrm{~h}^{-1}$. Irrigation volumes were quantified using tipping bucket rain gauges placed under drippers in the orchard.

Sap flow measurements were performed using the heat ratio method as described by Burgess et al. (2001) on six trees and calibrated as described by Taylor et al. (2013). These probe sets were inserted above the rootstock in the scion and below the first branch, with the probes being equally spaced around the trunk and randomly arranged, taking care to avoid any abnormalities in the trunk. Orchard transpiration was calculated as a weighted average of sampled trees based on a stem circumference survey at the start of the study and the consistent relationship between seasonal water use and stem circumference.

Reference evapotranspiration $\left(\mathrm{ET}_{\mathrm{o}}\right)$ was determined using the FAO Penman-Monteith equation (Allen et al.,1998) from weather data obtained from an automated weather station (AWS) located on each farm (within $2 \mathrm{~km}$ of the orchards). Transpiration crop coefficients $\left(K_{\mathrm{t}}\right)$ were determined from measured tree transpiration $(T)$ and reference evapotranspiration $\left(\mathrm{ET}_{\mathrm{o}}\right)$.

The procedure described by Allen and Pereira (2009) was used to estimate transpiration crop coefficients in the three orchards from measurements of fractional ground cover, tree height and daily weather data. $K_{\mathrm{t}}$ was adjusted for variation in vegetative cover by using a density coefficient $\left(K_{\mathrm{d}}\right)$ as follows:

$$
K_{\mathrm{t}}=K_{\mathrm{d}}\left(K_{\mathrm{t} \text { full }}\right)
$$


where $K_{\mathrm{t}}$ full is defined as the transpiration crop coefficient during peak plant growth for conditions having nearly full ground cover (or LAI > 3). $K_{\mathrm{t}}$ full for use with $\mathrm{ET}_{\mathrm{o}}$ can be approximated as a function of mean plant height and adjusted for climate as:

$$
K_{\mathrm{t} \text { full }}=F_{\mathrm{r}}\left(\min (1.0+0.1 h, 1.20)+\left[0.04\left(u_{2}-2\right)-0.004\left(R H_{\min }-45\right)\right]\left(\frac{h}{3}\right)^{0.3}\right)
$$

where $F_{\mathrm{r}}[0-1]$ is a relative adjustment factor for stomatal control, $h$ is mean monthly plant height $(\mathrm{m}), u_{2}$ is average monthly wind speed $\left(\mathrm{m} \mathrm{s}^{-1}\right)$ at $2 \mathrm{~m}$ for a particular growth period and $R H_{\min }$ is the average monthly minimum relative humidity in percent. Parameter $F_{\mathrm{r}}$ applies a downward adjustment $\left(F_{r} \leq 1.0\right)$ if the vegetation exhibits more stomatal control on transpiration than is typical of most annual agricultural crops, a situation that is typical of citrus (Kriedemann and Barrs,1981). $F_{\mathrm{r}}$ for full cover vegetation, based on the FAO PenmanMonteith equation and assuming full cover conditions was calculated as:

$$
F_{r} \approx \frac{\Delta+\gamma\left(1+0.34 u_{2}\right)}{\Delta+\gamma\left(1+0.34 u_{2} \frac{r_{l}}{100}\right)}
$$

where $r_{1}$ is mean leaf resistance for the vegetation in question $\left(\mathrm{s} \mathrm{m}^{-1}\right) ; \Delta$ is the slope of the saturation vapour pressure versus air temperature curve $\left(\mathrm{kPa}^{\circ} \mathrm{C}^{-1}\right)$ and $\gamma$ is the psychrometric constant $\left(\mathrm{kPa}^{\circ} \mathrm{C}^{-1}\right)$. Allen and Pereira (2009) suggest a value of $420 \mathrm{~s} \mathrm{~m}^{-1}$ for the initial and midseason periods and $150 \mathrm{~s} \mathrm{~m}^{-1}$ at the end of the season for citrus. Values of mean monthly $r_{1}$ for the study orchards were estimated by inverting Eq. 3, after solving for $F_{\mathrm{r}}$ by inverting Eq. 2, using known monthly values of $K_{\mathrm{t}}$ full. $K_{\mathrm{t}}$ full values were calculated using average monthly $K_{\mathrm{t}}$ (Eq. 1) and $K_{\mathrm{d}}$ values (Eq. 4), both determined from measured data, and inverting Eq. 1. Measurements of leaf resistance in the 'Rustenburg' Navel orchard were performed with a SC-1 Leaf porometer (Decagon Device Inc, Pullman, WA, USA) on 5 sunlit leaves per tree instrumented with sap flow equipment.

The density factor $\left(K_{\mathrm{d}}\right)$ was determined according to Allen and Pereira (2009) as follows:

$$
K_{\mathrm{d}}=\min \left(1, M_{L} f_{\mathrm{c} \text { eff }}, f_{\mathrm{c} \mathrm{eff}}^{\left(\frac{1}{1+h}\right)}\right)
$$

where $f_{\mathrm{c} \text { eff }}$ is the effective fraction of ground covered or shaded by vegetation [0.01-1] near solar noon, $M_{L}$ is a multiplier on $f_{\mathrm{c}}$ eff and is an attempt to simulate hydraulic resistances within the plant, with a value of 1.5 recommended for citrus (Allen and Pereira, 2009). $f_{\mathrm{c} \text { eff }}$ was calculated according to Allen et al. (1998).

The evaluation of model performance was done with the aid of statistical parameters including coefficient of determination $\left(\mathrm{R}^{2}\right)$, mean absolute error (MAE), root of the mean square error (RMSE) and index of agreement (D) of Willmott (1982). Model performance was considered satisfactory when $\mathrm{R}^{2}>0.8, \mathrm{MAE}<20 \%$ and $\mathrm{D}>0.8$ (de Jager, 1994).

\section{RESULTS AND DISCUSSION}

Transpiration in the orchard showed large day to day variation, which was largely determined by the prevailing climatic conditions, as seen from the $\mathrm{ET}_{\mathrm{o}}$ data (Fig. 1). However, it is evident that even though the atmospheric evaporative demand was highest during summer, there was no proportional increase in transpiration at this time. Whilst this kind of information is of significance to the commercial grower on whose farm the research was conducted, it is not always applicable and readily transferrable to many other citrus growing regions the world over, or even for different seasons. Reports on crop coefficients from different citrus orchards in different parts of the world have yielded very different crop coefficients. The adjustment of crop coefficients following the procedure of Allen and Pereira (2009) from measurements of canopy dimensions could therefore prove extremely useful in predicting water use in different orchards and citrus growing regions. 


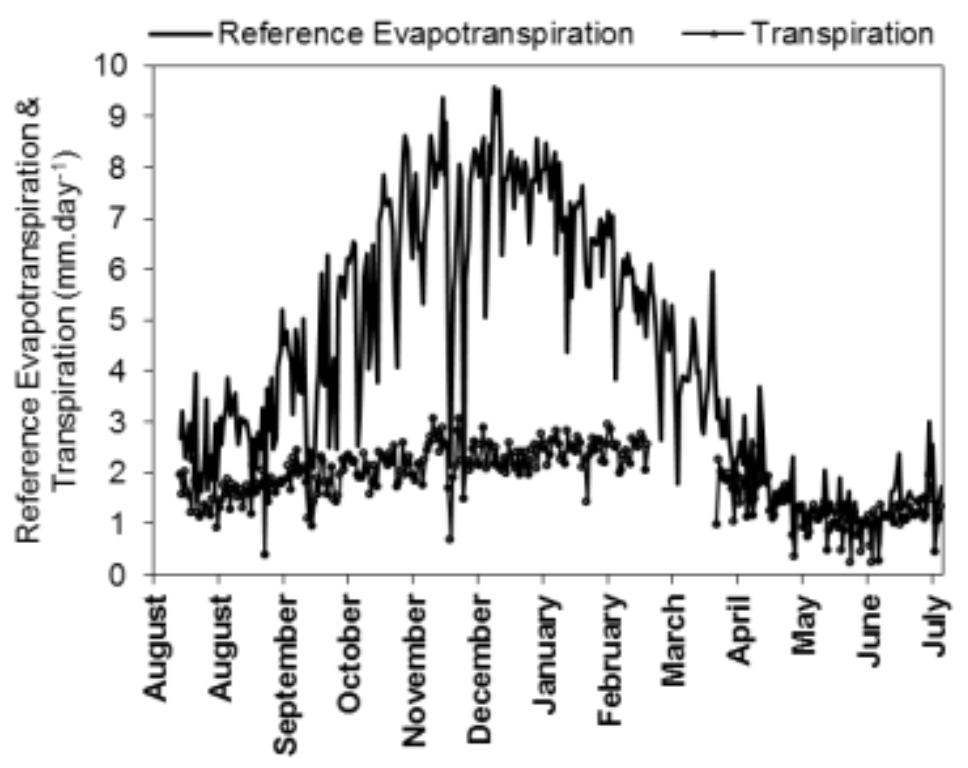

Fig. 1 Daily transpiration $\left(\mathrm{mm} \mathrm{day}^{-1}\right)$ and reference evapotranspiration $\left(\mathrm{mm} \mathrm{day}{ }^{-1}\right)$ for the 'Rustenburg' Navel orange orchard from 13 August 2010 to 12 August 2011 (transpiration data from 18 March to 17 April 2011 is missing as a result of a power failure).

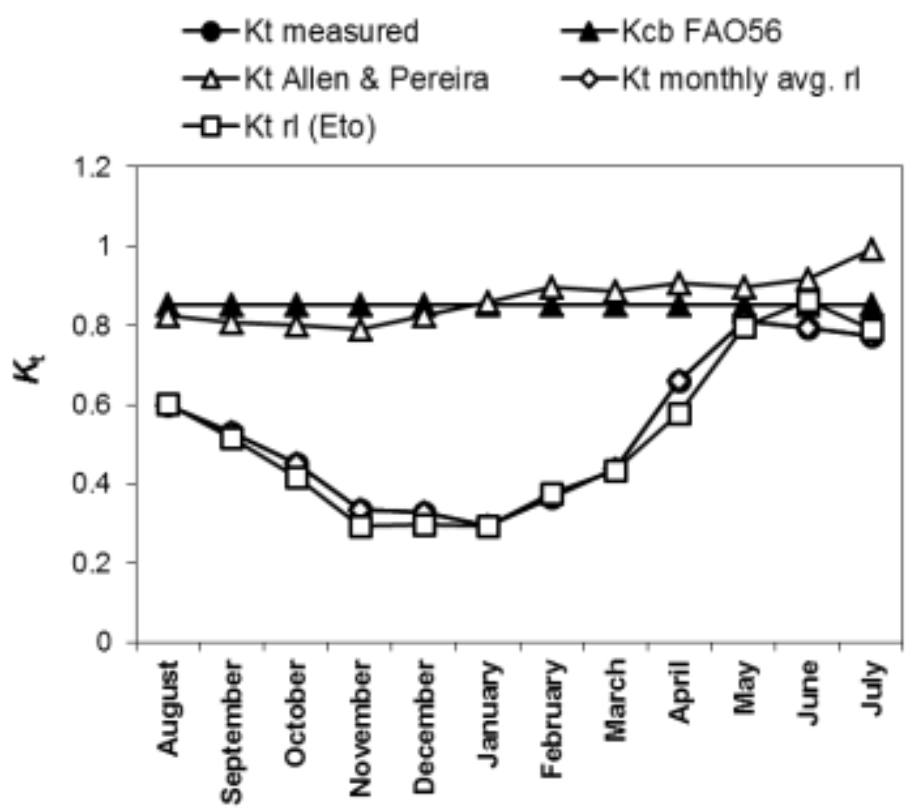

Fig. 2 Derived monthly transpiration crop coefficients $\left(K_{\mathrm{t}}\right)$ for 'Rustenburg' Navel orange orchard. Transpiration crop coefficients were determined using measured transpiration $\left(K_{\mathrm{t}}\right.$ measured), the method described in Allen and Pereira (2009) using the parameters given for citrus $\left(K_{\mathrm{t}}\right.$ Allen and Pereira), using estimates of monthly average $r_{1}$ values from transpiration data $\left(K_{\mathrm{t}}\right.$ monthly avg. $\left.r_{1}\right)$ and using $r_{1}$ estimated from the relationship with $\mathrm{ET}_{\mathrm{o}}\left(K_{\mathrm{t}} r_{1}\left(\mathrm{ET}_{\mathrm{o}}\right)\right)$. Also shown are FAO-56 standardised basal crop coefficients $\left(K_{\mathrm{cb}}\right.$ FAO-56) for a citrus orchard with $70 \%$ canopy cover as given by Allen and Pereira (2009).

$K_{\mathrm{t}}$ values for the measurement orchards were initially derived using parameters for citrus provided by Allen and Pereira (2009), where the value for $M_{L}$ was set to 1.5, apparent effective $r_{1}$ for the initial and midseason periods was $420 \mathrm{~s} \mathrm{~m}^{-1}$ and $r_{1}$ at the end of the season was $150 \mathrm{~s} \mathrm{~m}^{-1}$, and measured canopy dimensions and weather data were used. However, these transpiration coefficients $\left(K_{\mathrm{t}}\right.$ Allen and Pereira) did not compare well with the measured $K_{\mathrm{t}}$ 
values the orchard, and were at times in the season higher than the FAO-56 $K_{\mathrm{cb}}$ values for citrus given by Allen and Pereira (2009) (Fig. 2). If derived $K_{\mathrm{t}}$ values using the published fixed values of $r_{1}$, were to be applied over a season, they would have resulted in a $95 \%$ overestimation in the 'Rustenburg' Navel orchard.

The fixed parameters for citrus orchards given by Allen and Pereira (2009) were therefore not able to generate accurate transpiration crop coefficients for the orchards in this study, where specific orchard inputs were $f_{\mathrm{c}}$ eff, height and monthly averaged daily weather data. The overestimation of transpiration coefficients and crop water use (using the given citrus parameters) is likely a reflection of the greater stomatal control of transpiration in citrus than in most other crops, which is attributed to high resistances to water transport within the plant (Kriedemann and Barrs, 1981; Sinclair and Allen, 1982; van Bavel et al., 1967). Whilst Allen and Pereira (2009) account for this by including their $F_{\mathrm{r}}$ parameter, which is used as a downward adjustment on crop coefficients for crops which exhibit more stomatal control on transpiration than most other agricultural crops, the $r_{1}$ value of $420 \mathrm{~s} \mathrm{~m}^{-1}$ suggested by the authors may be too low, especially during hot summer months, when vapor pressure deficit (VPD) increases. More appropriate values for $r_{1}$ were therefore estimated using measured data (Allen and Pereira, 2009) and it is clear that mean monthly estimated $r_{1}$ (Fig. 3) is not constant throughout the season and varies with leaf age and climatic conditions, as found by van Bavel et al. (1967). As a result of the greater degree of stomatal control of transpiration in citrus, which is more evident at high VPDs (Sinclair and Allen, 1982), leaf resistance increased in the summer months, which results in a disproportionate increase in $\mathrm{ET}_{\mathrm{o}}$ relative to transpiration and therefore a lowering of the appropriate crop coefficient.

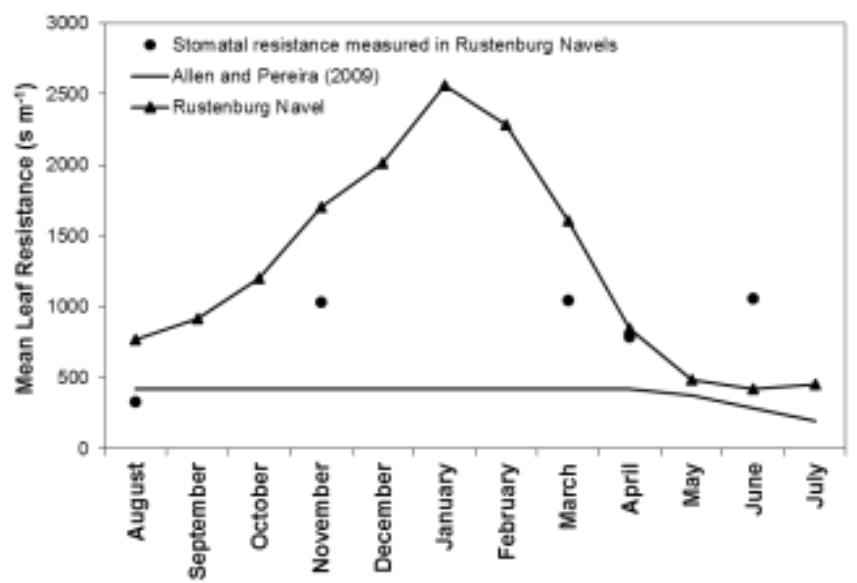

Fig. 3 Monthly mean leaf resistances calculated using the procedure outlined in Allen and Pereira (2009), compared with the value suggested by Allen and Pereira (2009) for citrus and daily stomatal resistance measured in the 'Rustenburg' Navel orange orchard in Citrusdal.

As the calculated monthly average $r_{1}$ values were derived directly from measured $K_{\mathrm{t}}$ values $\left(K_{\mathrm{t}}\right.$ measured), it is not surprising that they provided very good estimates of $K_{\mathrm{t}}\left(K_{\mathrm{t}}\right.$ monthly avg. $r_{1}$ ) for the orchard (Fig. 2), with the two plots sitting perfectly on top of one another. This indicates that a change in leaf resistance in a citrus orchard over the season needs to be taken into account. Whilst it is acknowledged that these $r_{1}$ values contain artefacts of the $K_{\mathrm{t}}$ full estimates, weather data error and the constructs of Eq. 2 and Eq. 3, and should only be used with confidence for the estimation of $F_{\mathrm{r}}$ (Allen and Pereira, 2009), a comparison of these resistance values (ranging from 419 to $2694 \mathrm{~s} \mathrm{~m}^{-1}$ ) with published measured data indicates that leaf and canopy resistances higher than $420 \mathrm{~s} \mathrm{~m}^{-1}$ are routinely found in citrus. In the summer rainless months in Israel, daily leaf resistances in Shamouti orange varied 
from 500 to $2000 \mathrm{~s} \mathrm{~m}^{-1}$ (Cohen and Cohen, 1983) and in winter in Zimbabwe, resistances in young Navel orange trees varied from 200 to $8280 \mathrm{~s} \mathrm{~m}^{-1}$ (Dzikiti et al., 2007). Pérez-Pérez et al. (2008) also reported stomatal resistances ranging between 295 and $830 \mathrm{~s} \mathrm{~m}^{-1}$ in oranges throughout the fruit growth period in Southern Spain. However, average daily stomatal resistance, measured in citrus orchards in the winter rainfall region of South Africa, was between 300 and $1000 \mathrm{~s} \mathrm{~m}^{-1}$ (Fig. 3), which was considerably lower than the $r_{1}$ values of between 530 and $2694 \mathrm{~s} \mathrm{~m}^{-1}$ for this period, but generally the trend was very similar. The $r_{1}$ values in Fig. 3 thus seem to be a little higher than actual $r_{1}$ could be expected to be in a citrus orchard, and may therefore be slightly biased by the procedure outlined by Allen and Pereira (2009), indicating that measured leaf resistances could potentially underestimate crop coefficients when used in Eq. 3.

Whilst calculating mean $r_{1}$ values resulted in the accurate estimation of $K_{\mathrm{t}}$ values, it is the estimation of mean $r_{1}$, without measured transpiration, that really hinders the ease with which this approach can be used to accurately estimate crop coefficients for different citrus orchards. In order to make this approach more transferrable, the parameterization of $r_{1}$ was attempted for the 'Rustenburg' Navels with climatic data in the 2010/11 season, to determine if there was a reproducible relationship between $r_{1}$ and a routinely measured weather variable, such as relative humidity, VPD or $\mathrm{ET}_{\mathrm{o}}$. The most reproducible empirical relationship on a monthly basis was found between $\mathrm{ET}_{\mathrm{o}}\left(\mathrm{mm} \mathrm{day}^{-1}\right)$ and mean estimated $r_{1}\left(\mathrm{~s} \mathrm{~m}^{-1}\right)$ (Fig. 4). When comparing seasonal estimates of transpiration based on estimated $K_{\mathrm{t}}$ values from this relationship, transpiration was underestimated by $0.1 \%$ in the $2010 / 11$ season and by $11 \%$ in the 2011/12 season in the 'Rustenburg' Navel orchard. The performance of the model, as determined by statistical parameters, was good for the two seasons in the orchard, as the MAE was less than $20 \%$ and D greater than 0.8. In the 'Rustenburg' Navel orchard in the 2010/11 season, good estimates of water use were obtained throughout the season (Fig. 5). However, in the subsequent 2011/12 season, water use was underestimated during the peak water use period from October to March (Fig. 5), but model performance was still satisfactory (MAE $=14 \%$ and $\mathrm{D}=0.89$ ).

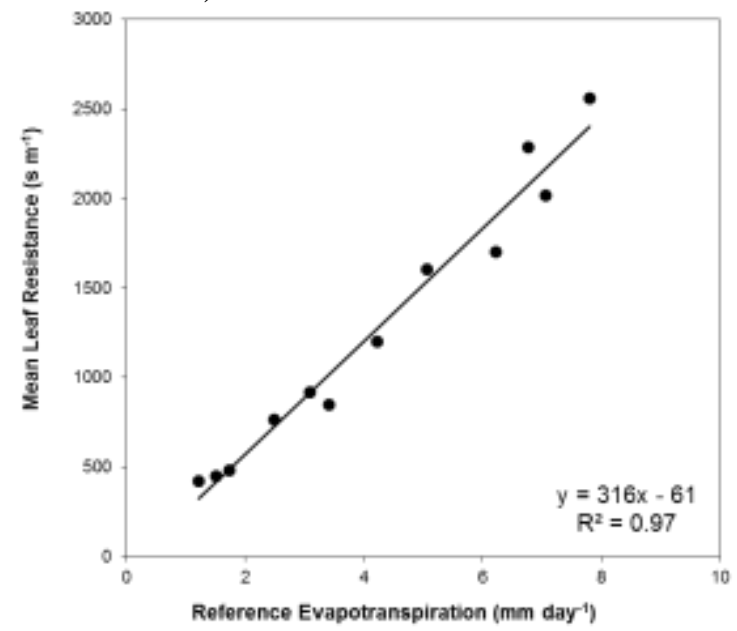

Fig. 4 Relationship between mean leaf resistance and reference evapotranspiration (ET ${ }_{\mathrm{o}}$ ) for the 'Rustenburg' Navel orange orchard in the 2010/11 season. 

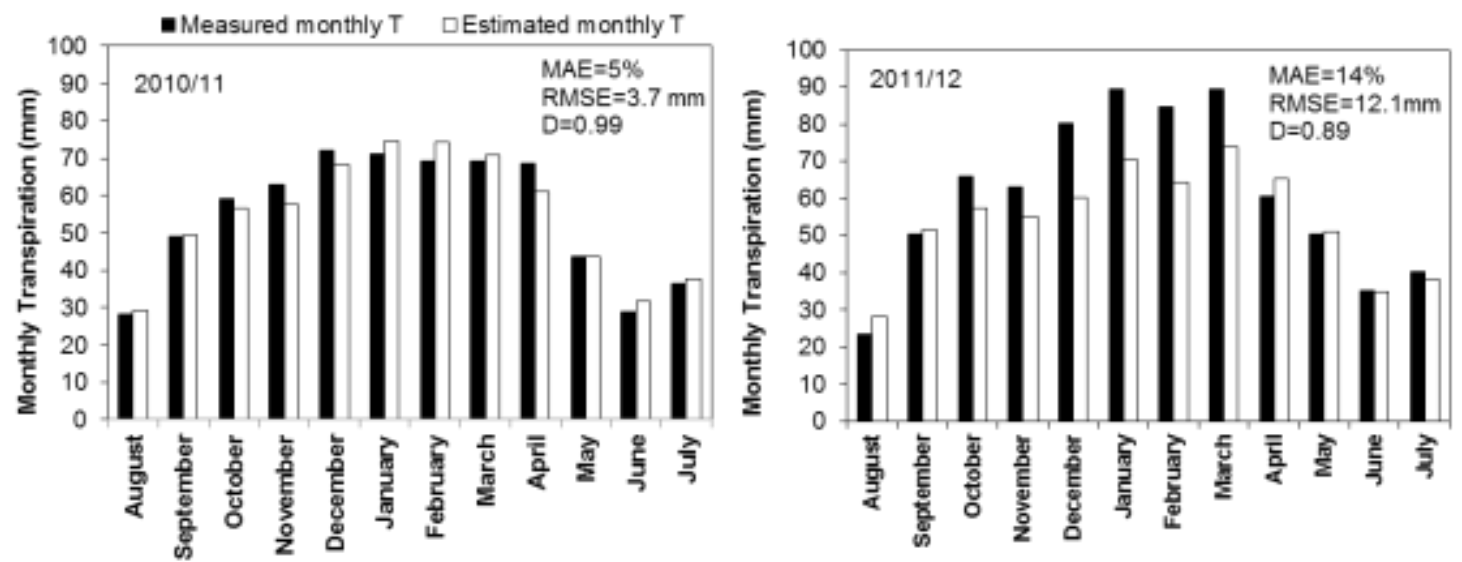

Fig. 5 Comparison between monthly measured and estimated transpiration using $K_{\mathrm{t}}$ values derived from mean leaf resistance, estimated from the relationship between reference evapotranspiration and mean leaf resistance, for the 'Rustenburg' Navel orange orchard in the 2010/11 and 2011/12 seasons. MAE is mean absolute error, RMSE is root of the mean square error and D is the index of agreement of Willmot (1982).

The use of a simple empirical relationship between $\mathrm{ET}_{\mathrm{o}}$ and $r_{\mathrm{l}}$, together with the procedure outlined by Allen and Pereira (2009), provided good seasonal transpiration estimates in the study orchards, implying that this method could be used for irrigation planning purposes and water licensing. However, the inability to predict water use accurately on a monthly basis for most of the season limits the use of this procedure for irrigation scheduling, which will require more reliable estimates of $r_{1}$. This is not unexpected, as stomatal conductance is known to be regulated by a number of factors, which includes radiant flux energy, ambient $\mathrm{CO}_{2}$ concentration, leaf to air vapour pressure deficit, leaf temperature, leaf water status, and hydraulic limitations to leaf water supply (Jarvis, 1976; Sperry et al., 2002) and it is usually a combination of these factors that determines stomatal conductance. The solution for better prediction of leaf resistances may be to use more mechanistic models which can predict canopy conductance based on canopy size, environmental variables and sink strength or potential yield. Similar approaches have been undertaken by Oguntunde et al. (2007) and Villalobos et al. (2009; 2013) and have shown some promise, but the ability of these models to predict citrus water use need to be verified in orchards with different canopy sizes and in different climatic regions.

\section{ACKNOWLEDGEMENTS}

This is a solicited project, initiated, managed and funded by South Africa's Water Research Commission (Project K5/1770, Water use of fruit tree orchards), with co-funding from the South African National Department of Agriculture, Forestry and Fisheries. We are also grateful to Schoeman Boerdery for the use of their orchard, in particular J Burger, H Schoeman and B du Toit and to Patrysberg Farm, in particular C Junius and J Toerien.

\section{REFERENCES}

Allen, R.G. and Pereira, L.S. 2009. Estimating crop coefficients from fraction of ground cover and height. Irrig. Sci. 28:1:17-34.

Allen, R.G. Pereira, L.S. Raes, D. and Smith, M. 1998. Crop evapotranspiration: guidelines for computing crop water requirements, Irrigation and Drainage Paper 56. United Nations FAO, Rome http://www.fao.org/docrep/X0490E/X0490E00.htm.

Annandale, J. and Stockle, C. 1994. Fluctuation of crop evapotranspiration coefficients with weather: a sensitivity analysis. Irrig. Sci. 15:1:1-7. 
Burgess, S.S.O. Adams, M.A. Turner, N.C. Beverly, C.R. Ong, C.K. Khan, A.A.H. and Bleby, T.M. 2001. An improved heat pulse method to measure low and reverse rates of sap flow in woody plants. Tree Physiol. 21:589-598.

Cohen, S. and Cohen, Y. 1983. Field studies of leaf conductance response to environmental variables in citrus. J. Appl. Ecol. 20:561-570.

de Jager, J. 1994. Accuracy of vegetation evaporation ratio formulae for estimating final wheat yield. Water SA 20:307-314.

Dzikiti, S. Steppe, K. Lemeur, R. and Milford, J. 2007. Whole-tree level water balance and its implications on stomatal oscillations in orange trees [Citrus sinensis(L.) Osbeck] under natural climatic conditions. J. Exp. Bot. 58:7:1893-1901.

Jarvis, P. 1976. The interpretation of the variations in leaf water potential and stomatal conductance found in canopies in the field. Philos. Trans. Roy. Soc. Lond. Ser B: Biol Sci 273:927:593-610.

Kriedemann, P. and Barrs, H. 1981. Citrus orchards. p. 325-417. In: T.T. Kozlowski (ed.), Water Deficits and Plant Growth, Academic Press, New York.

Oguntunde, P.G. van de Giesen, N. and Savenije, H.H.G. 2007. Measurement and modelling of transpiration of a rain-fed citrus orchard under subhumid tropical conditions. Agric. Water Manage. 87:2:200-208.

Pérez-Pérez, J. Romero, P. Navarro, J. and Botía, P. 2008. Response of sweet orange cv 'Lane late' to deficit irrigation in two rootstocks. I: water relations, leaf gas exchange and vegetative growth. Irrig. Sci. 26:5:415425 .

Sinclair, T. and Allen, L. 1982. Carbon dioxide and water vapour exchange of leaves on field-grown citrus trees. J. Exp. Bot. 33:6:1166-1175.

Sperry, J. Hacke, U. Oren, R. and Comstock, J. 2002. Water deficits and hydraulic limits to leaf water supply. Plant, Cell Environ. 25:2:251-263.

Taylor, N. Ibraimo, N. Annandale, J. Everson, C. Vahrmeijer, J. and Gush, M. 2013. Are sap flow measurements useful for determining water use of fruit orchards, when absolute values are important? IX International Workshop on Sap Flow 991. p.77-83.

Testi, L. Villalobos, F. and Orgaz, F. 2004. Evapotranspiration of a young irrigated olive orchard in southern Spain. Agric. For. Meteorol. 121:1:1-18.

van Bavel, C. Newman, J. and Hilgeman, R. 1967. Climate and estimated water use by an orange orchard. Agric. Meteorol. 4:1:27-37.

Villalobos, F.J. Testi, L. and Moreno-Perez, M.F. 2009. Evaporation and canopy conductance of citrus orchards. Agric.Water Manage. 96:4:565-573.

Villalobos, F.J. Testi, L. Orgaz, F. García-Tejera, O. Lopez-Bernal, A. González-Dugo, M.V. Ballester-Lurbe, C. Castel, J.R. Alarcón-Cabañero, J.J. Nicolás-Nicolás, E. Girona, J. Marsal, J. and Fereres, E. 2013. Modelling canopy conductance and transpiration of fruit trees in Mediterranean areas: A simplified approach. Agric. For. Meteorol. 171-172:0:93-103.

Willmott, C.J. 1982. Some comments on the evaluation of model performance. Bull. Am. Meteorol. Soc. 63:11:1309-1313. 